\title{
Glycemic Index Values of Rice Varieties that are Commonly Available in Markets in Bangladesh
}

\author{
Enamul Kabir', Md Tofazzal Hossain', Mohammad Anowar Hossain', \\ Shuma Rani Ray ${ }^{1}$, Muhammad Javidul Haque Bhuiyan ${ }^{1^{*}}$ \\ ${ }^{1}$ Department of Biochemistry and Molecular Biology, Faculty of Agriculture, \\ Bangladesh Agricultural University, Mymensingh 2202, Bangladesh
}

\begin{abstract}
Glycemic Index (GI) of six common rice varieties in the local markets of Bangladesh was assessed and categorized in this study to investigate manipulative varietal performance for the time being. After overnight fasting, each of ten selected healthy non-diabetic volunteers (males and females in ratio of 1:1) was fed with reference food (50 g glucose) and test foods (50 g carbohydrate-containing different rice varieties) in every two days intervals. After feeding, glucose levels $(\mathrm{mmol} / \mathrm{l})$ were measured at 0 , 15, 30, 45, 60, 90 and 120 minutes. Incremental Area Under Curve (IAUC) of reference food and test food (avoiding the area beneath the baseline of reference food) was calculated to measure GI values. Amylose content (\%) of different test foods was measured from the standard curve obtained from the spectrophotometric analysis after alcoholic-alkaline gelatinization that was followed by acidification and iodine mixing. The result showed that the GI values were $59.7 \pm 3.4 ; 50.5 \pm 2.6 ; 57.8 \pm 2.8 ; 51.3 \pm 2.3$; $56.9 \pm 3.9$ and $44.6 \pm 2.1$, while the amylose content $(\%)$ were $23.6 \pm 0.6 ; 26.7 \pm 0.9 ; 21.3 \pm 0.7 ; 28.3 \pm 1.1$; $22.2 \pm 2.3$ and $29.8 \pm 1.5$ for Nizershail, BRRI Dhan 29, Chinigura, Kalijira, Hybrid Hera Dhan 12 and Sworna, respectively. Moreover, the existing inverse relationship between the GI values and amylose content in this study was similar to other researchers' findings. Categorization of the test foods based on the observed GI values ranked Sworna, BRRI Dhan 29 and Kalijira as low GI rice varieties that could be beneficial for consumption by diabetics as well as healthy individuals.
\end{abstract}

Keywords: Bangladesh, glycemic index, market, rice varieties

\section{INTRODUCTION}

Rice is not only a staple food in Bangladesh, but also a major cereal foodstuff for about half of the world's population. It is noteworthy that starch as a major constituent (about $72 \%$ to $75 \%$ ) of rice directly raises the postprandial blood glucose and insulin response in mammals (Hewson-Hughes et al. 2011). So, rice-based carbohydrate foodstuffs consumption should be judicially performed in diabetic individuals for controlling diabetes.

Diabetes mellitus has become a leading cause of death and disability worldwide. Moreover, diabetes-related complications like cardiovascular disease, peripheral artery disease, retinopathy, nephropathy and depression could be the risk factors, especially for the South Asian people (Safita et al. 2016). According to a metaanalysis (from 2001 to 2010), the incidence of diabetes had substantially increased from $5 \%$ to
9\% among the Bangladeshi adults (Saquib et al. 2012). Such increasing trend might create an unhealthy population, which could be a burden rather than a resource for this country in the long run.

Management of diabetes is most critical and even could be difficult sometimes to be accomplished due to traditional lifestyle. Many people are not quite ready to compromise with their conventional carbohydrate intake, maintain a disciplined daily life with regular exercise, and expense extra money for medication. Various carbohydrate foodstuffs show different range of effects on the blood glucose level and hormonal response after having a meal. Thus, it is important to consider not only the quantity, but also the quality of carbohydrate foodstuffs while considering diabetes management. Low Glycemic Index (GI) rice varieties could be a good choice in this regard (Pinhero et al. 2016).

\footnotetext{
"Corresponding Author: tel: +8801718084131, email: mjhbhuiyan@bau.edu.bd
} 
On the contrary, high glycemic index foodstuffs are associated with the development of type 2 diabetes (Bhupathiraju et al. 2014).

Generally, GI gives an idea about how fast the body converts the carbohydrate foodstuffs into glucose. This term was firstly introduced by Jenkins et al. (1981), who proposed carbohydrates' ranking based on a scale from 0 to 100 according to the postprandial impact on blood glucose level. High GI foods $(\geq 70)$ are rapidly digested, absorbed and metabolized, resulting in increased blood glucose level. On the contrary, low GI foods $(\leq 55)$ improve the metabolic variables in diabetic, hyperlipidemic or even in healthy individuals by prolonging satiety (GI newsletter 2019). Amylose content, an inherent chemical property in the starch structure, could be another influential factor to interpret the observed GI values in this study, since it exhibits an inverse relationship with GI values (Jeevetha et al. 2014). In this context, for the betterment of diabetes management, we included six commonly consumed rice varieties that are available in markets in Bangladesh (like Nizershail, BRRI Dhan 29, Chinigura, Kalijira, Hybrid Hera Dhan 12 and Sworna) in this study to assess their GI values and categorize them accordingly. The GI values of BRRI Dhan 29 and Chinigura from these selected rice varieties were assessed before in previous experiments. However, over time the varietal purity of all these varieties is in doubt. So, we chose the common varieties readily available at the local market to assess the real situation of the GI values of selected varieties.

\section{METHODS}

\section{Design, location, and time}

In vivo experiment was conducted in the Food Bioscience Laboratory of Department of Biochemistry and Molecular Biology, Bangladesh Agricultural University, from July 2018 to June 2019.

\section{Sampling}

Ten healthy non-diabetic volunteers (males and females in ratio of 1:1) of different ages ranging from 22 to 45 years were recruited in this study. The subjects who had normal body weight (BMI that ranges from 18.5 to $24.9 \mathrm{~kg}$ / $\mathrm{m}^{2}$ as per WHO recommendation) and were free from any illness, food allergy, and medications were included. They were requested to maintain a regular diet and activity schedule throughout the experiment. The study protocol was approved by the Diabetic Association of Bangladesh (DABHT73/2018) following the guideline described in the Declaration of Helsinki. Before participation, all the subjects were well informed and their written consents were taken as well.

\section{Data collection}

Test foods. Six rice varieties of different types like local variety (Nizershail), high-yielding variety (BRRI Dhan 29), aromatic variety (Chinigura, Kalijira), hybrid variety (Hybrid Hera Dhan 12), and inbred variety (Sworna) were taken in this experiment to assess their GI values. All these common verities were purchased from the local market. Aromatic varieties were nonparboiled as well as fine, while the other varieties were parboiled and coarse. Fifty grams available carbohydrate-containing rice of each variety was cooked for $21 \pm 1$ minutes in an electric rice cooker (rice and water ratio was 1:3). The cooked rice was kept in the open air for 30 minutes to reach room temperature and was finally served to each of the subjects. It took around 10 minutes to ingest the test food from the first bite. The performance of each test food was measured only once. During testing, the subjects were encouraged to be acquainted with minimum physical activity.

Proximate analysis of test foods. Standard protocols (AOAC 2019) were followed and calculations were performed accordingly to determine the proximate parameters. All the samples were oven-dried $\left(\right.$ at $\left.105^{\circ} \mathrm{C}\right)$ until constant weights were achieved for moisture content (\%) determination as follows:

$$
\left(\frac{\text { Initial weight of crucible }- \text { Final weight of crucible }}{\text { Weight of sample }}\right) \times 100
$$

With the help of usual non-enzymatical method, ash content was measured. Dry samples were further kept in muffle furnace for five hours ignition at $600^{\circ} \mathrm{C}$ to assess ash content (\%) using the following formula:

$$
\left(\frac{\text { Initial weight of crucible }- \text { Final weight of crucible }}{\text { Weight of sample }}\right) \times 100
$$

Dietary fiber content (\%) was estimated by AOAC (2019) method and the percentage was calculated as follows: $\frac{\text { Loss of weight }}{\text { Weight of sample }} \times 100$. Micro- 
Kjeldahl apparatus was used to determine the percent $\mathrm{N}$ followed by protein content (SaezPlaza et al. 2013) using this formula:

$$
\text { \%Nitrogen }=\left(\frac{(T S-T B) \times \text { Normolity of acid } \times \text { meq of } N)}{\text { Weight of sample }}\right) \times 100
$$

where, TS=titer value for sample, $\mathrm{TB}=$ titer value of the blank, and meq of $\mathrm{N}=0.014$, and thus, finally: \%Protein $=\%$ Nitrogen $\times 5.5$ (Conversion factor). In the Soxhlet apparatus, $250 \mathrm{~g}$ ground material ( 80 mesh) of each rice variety was taken to determine the fat content. The extraction was performed on a water bath for six hours with $500 \mathrm{ml} \mathrm{n}$-hexane as extracting solvent. After the oil extraction, the excess solvent was distilled off under reduced pressure in a rotary evaporator. Total available carbohydrate content $(\%)$ was measured using the formula according to FAO (2004) as follows:

$$
100-(\% \text { Moistur }+\% \text { Ash }+\% \text { Protein }+\% \text { Fiber }+\% \text { Fat })
$$

Reference food. Fifty grams of glucose (Glucon-D, Heinz India Pvt. Ltd, India) was dissolved in $200 \mathrm{ml}$ water and was used as the reference food. Performance of reference food on blood glucose level was measured every two days before assessing the test foods performance to avoid the carry-over effect (Brouns et al. 2005). On the other hand, at least ten days were maintained as washout period between two test foods' trials.

Blood glucose measurements. After 10-12 hours overnight fasting, the subjects were ready to be incorporated with the testing process in the morning. Fasting blood glucose levels (mmol/l) were measured at 20 minutes and 0 minute before the consuming the food (both reference food and test food) and their mean values was fixed as the baseline value. After having the meal at 15, $30,45,60,90$ and 120 minutes, blood glucose levels were again measured. Blood glucose level measurement was performed by pricking finger using a glucometer (Bioland, Model: G-423E, China).

Glycemic index calculation. The incremental area under curves (IAUC) for the blood glucose level variation during the testing of reference (glucose) and test (rice varieties) foods was calculated geometrically in the MSExcel-2007 program by trapezoid rule ignoring the area beneath baseline value of reference food (FAO/WHO 1998). IAUC of reference foods were always assumed to be 100 . Compare with the reference food, the converted value from respective IAUC of test foods were calculated, indicating their subsequent GI values. After having all the GI values, GI classification was performed accordingly (Jenkins et al. 1981).

Determination of amylose content (\%). Amylose content (\%) was estimated according to the established procedure (Duan et al. 2012). Finely powdered $10 \mathrm{mg}$ test sample was taken into Erlenmeyer flask with $1 \mathrm{ml} \mathrm{95 \%} \mathrm{ethanol} \mathrm{and}$ $9 \mathrm{ml} 1 \mathrm{~N} \mathrm{NaOH}$, warmed for 5 minutes in water bath to be gelatinized with the starch and made up the volume with distilled water to $100 \mathrm{ml}$. Five $\mathrm{ml}$ of this solution was acidified $(1 \mathrm{ml} 1 \mathrm{~N}$ acetic acid) with iodine solution $(2 \mathrm{ml})$ and made the volume up to $100 \mathrm{ml}$, allowed to keep for 20 minutes before taking optical density reading. For standard amylose solution, $100 \mathrm{mg}$ anhydrous rice amylose (JT Baker Chemical Co. Phillips-Burge, New Jersey, USA) was taken to prepare $100 \mathrm{ml}$ stock solution with $10 \mathrm{ml} 95 \%$ ethanol and $90 \mathrm{ml}$ $1 \mathrm{~N} \mathrm{NaOH}$. From the stock solution, $0.25 \mathrm{mg} \%$, $0.5 \mathrm{mg} \%, 0.75 \mathrm{mg} \%, 1 \mathrm{mg} \%, 1.25 \mathrm{mg} \%, 1.5$ $\mathrm{mg} \%, 1.75 \mathrm{mg} \%$, and $2 \mathrm{mg} \%$ working solutions were prepared along with acidification (acetic acid) and mixing iodine solution. Optical density was measured using a UV spectrophotometer (Renonlab, Model-722G, China) at $625 \mathrm{~nm}$ and used to prepare a standard curve accordingly. From the standard curve, test samples' amylose content $(\%)$ were subsequently calculated.

\section{Data analysis}

Statistical analysis was performed by using the SPSS (version 11.0.1, USA) software. Data were presented with mean, Standard Deviation (SD), Standard Error (SEM), statistical significance of $p<0.01$ and $p<0.05$. Since, the data were normally distributed, the significant difference among the GI values of test foods was tested by generalized linear model (ShapiroWilks statistics). Amylose content in different test foods was grouped using Duncan's Multiple Range Test (DMRT).

\section{RESULTS AND DISCUSSION}

\section{Observation of study subjects}

The anthropometric measurements like height, weight, BMI, fasting blood glucose level, and blood pressures were recorded at fasting conditions (shown in Table 1). 
Table 1. Demographic characteristics of study subjects $(\mathrm{n}=10)$

\begin{tabular}{lc}
\hline \multicolumn{1}{c}{ Characteristics } & Mean $\pm \mathrm{SD}$ \\
\hline Age (Years) & $35.9 \pm 7.56$ \\
Body weight $(\mathrm{kg})$ & $55.63 \pm 4.98$ \\
Height $(\mathrm{m})$ & $1.63 \pm 0.052$ \\
BMI $\left(\mathrm{kg} / \mathrm{m}^{2}\right)$ & $21.15 \pm 2.13$ \\
Fasting glucose level (mmol $/ \mathrm{l})$ & $5.3 \pm 0.5$ \\
Blood pressure & \\
$\quad$ & \\
$\quad$ Systolic $(\mathrm{mmHg})$ & $115 \pm 8.55$ \\
$\quad$ Diastolic $(\mathrm{mmHg})$ & $73 \pm 10.12$ \\
\hline
\end{tabular}

Values are shown as mean with standard deviation BMI: Body Mass Index

No statistical significance was observed among the demographic characteristics and the GI values, IAUC values as well as amylose content. Since the residual effects were found normal the data are not included here.

\section{Nutrient composition and cooking properties of test rice varieties}

The selected rice varieties were procured from the local market to assess the manipulative varietal performance, specially related the GI content. Their nutrient compositions are shown in Table 2.

\section{Variations in blood glucose level ( $\mathrm{mmol} / \mathrm{l})$ with different rice varieties}

Blood glucose level (mmol/l) fluctuations for 2 hours after consuming different test foods (rice varieties) along with reference food (glucose) are presented in Figure $1(\mathrm{a}-\mathrm{f})$. Data were presented as mean $\pm \mathrm{SEM}$. There was no significant difference between the responses of test foods and reference foods at 0 minute. The baseline value for each test food was fixed by glucose level of reference food at 0 minute. Above this baseline value, both the reference food and test foods showed a varied significance level as $\mathrm{p}<0.01$ and $\mathrm{p}<0.05$. For all cases, at 120 minutes, no significant variations in blood glucose levels were obtained as expected.

\section{Calculation of GI values and their categorization}

Table 3 indicates the calculated summation of IAUC (mmol/l.min) for each test food. The mean \pm SD of different rice varieties ranged from $112.1 \pm 6.3$ to $185.3 \pm 12.7 \mathrm{mmol} / \mathrm{l} . \mathrm{min}$. GI values are also presented as mean \pm SD. From the table we got that low GI rice varieties were BRRI Dhan 29, Kalijira, and Sworna.

\section{Amylose content (\%)}

Amylose content (\%) in each test food is presented in Figure 2 as mean \pm SD. The lowest amylose content (\%) was observed to be $21.3 \pm 0.7$ in Chinigura and the highest was $29.8 \pm 1.5$ in Sworna. According to the range test (DMRT), all the test foods were grouped. High amylose content rice varieties were BRRI Dhan 29, Kalijira, and Sworna. On the other hand, Nizershail, Chinigura and Hybrid Hera Dhan 12 were grouped as low amylose content rice varieties.

In this experiment, we involved different types of rice varieties. From these rice varieties,

Table 2. Proximate composition and cooking properties of different test foods

\begin{tabular}{lcccccccc}
\hline \multicolumn{1}{c}{ Rice variety } & $\begin{array}{c}\text { Moisture } \\
(\%)\end{array}$ & $\begin{array}{c}\text { Ash } \\
(\%)\end{array}$ & $\begin{array}{c}\text { Dietary } \\
\text { fiber }(\%)\end{array}$ & $\begin{array}{c}\text { Fat } \\
(\%)\end{array}$ & $\begin{array}{c}\text { Protein } \\
(\%)\end{array}$ & $\begin{array}{c}\text { Available } \\
\text { carbohydrate } \\
(\%)\end{array}$ & $\begin{array}{c}\text { Rice }(\mathrm{g}) \\
\text { cooked per } \\
\text { serving }\end{array}$ & $\begin{array}{c}\text { Cooking } \\
\text { time } \\
(\mathrm{min})\end{array}$ \\
\hline Nizershai & 11.6 & 1.57 & 1.2 & 2.8 & 6.7 & 76.13 & 65.7 & 20 \\
BRRI Dhan 29 & 11.3 & 1.43 & 1.2 & 1.9 & 6.99 & 77.18 & 64.8 & 21 \\
Chinigura & 12.3 & 1.38 & 1.3 & 2.3 & 6.24 & 76.48 & 65.4 & 20 \\
Kalijira Hybrid Hira & 12.8 & 1.02 & 0.9 & 2.31 & 7.1 & 75.87 & 65.9 & 22 \\
Dhan 12 & 12.5 & 1.29 & 1.0 & 2.1 & 6.69 & 76.42 & 65.4 & 22 \\
Sworna & 13.8 & 1.81 & 1.4 & 4.12 & 8.8 & 70.07 & 71.4 & 21 \\
\hline
\end{tabular}

According to the available carbohydrate content different amount of rice varieties was calculated before serving to the subjects for further analysis 
Glycemic index of rice varieties in Bangladesh
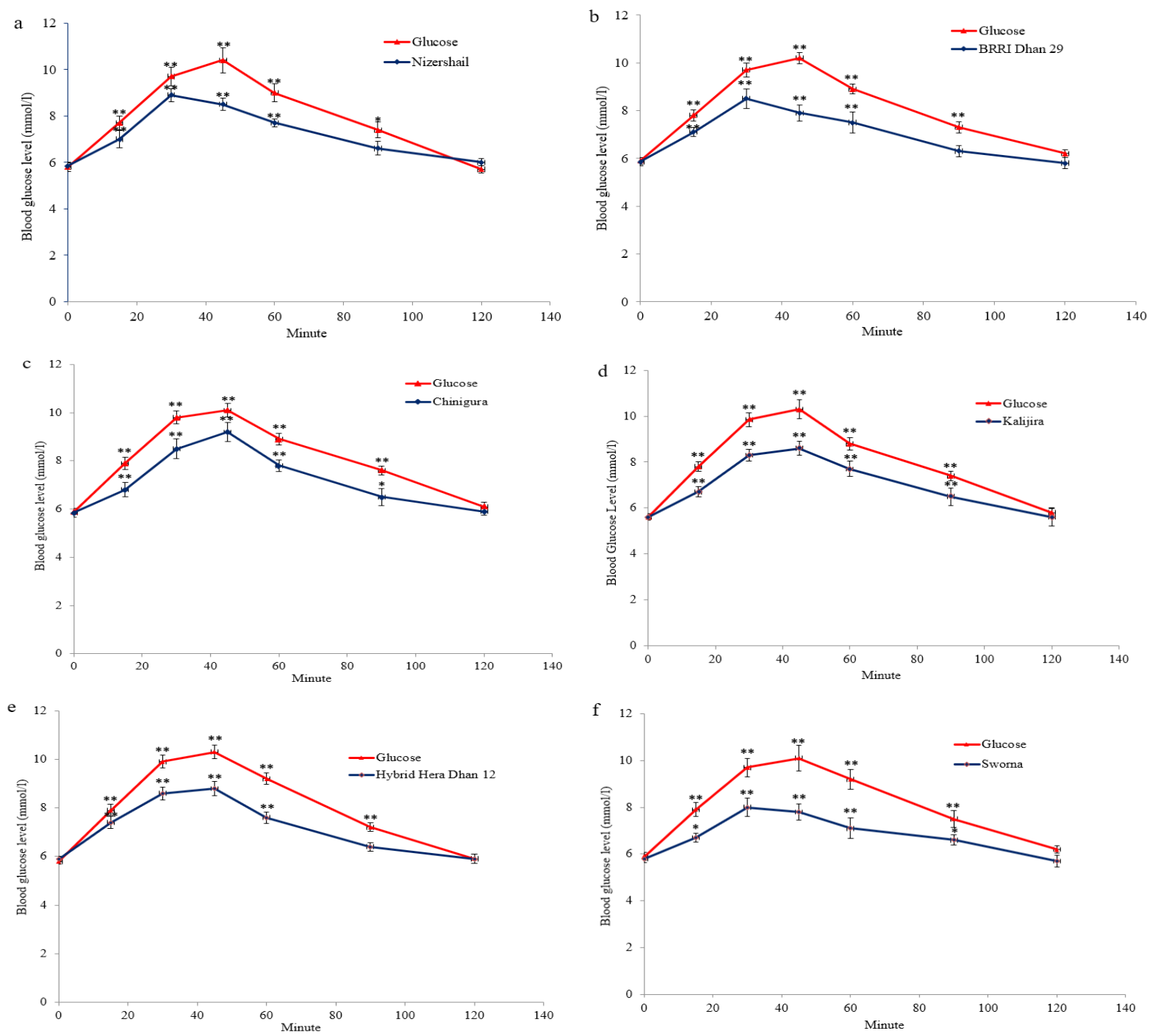

Figure 1. (a-f): Blood glucose level ( $\mathrm{mmol} / \mathrm{l})$ variations at different time points after 2 hours of glucose (reference food) and rice (test food) consumption: Figures a; b; $c$; $;$; e and $f$ indicates glucose responses of Nizershail; BRRI Dhan 29; Chinigura; Kalijira; Hybrid Hera Dhan 12; and Sworna with ${ }^{*}$ of $\mathrm{p}<0.05$ and $^{* *}$ of $\mathrm{p}<0.01$ respectively

Chinigura and Kalijira were non-parboiled and the others were parboiled. The result showed that BRRI Dhan 29, Kalijira and Sworna rice were low GI ranked rice varieties. Again, these varieties had high amylose content subsequently. A significant association between high GI foodstuffs and type 2 diabetes prevalence has been exhibited previously (Bhupathiraju et al. 2014).

People of this country are most likely large consumer of rice which ultimately enhances diabetes. Moreover, inclusion of high GI rice in regular diets could be further more devastating for managing diabetes. Rice cultivation in different geographical regions may involve a varied range of grain morphology, water absorption, macronutrients, dietary fiber and amylose content (Bhonsle \& Sellappan 2010). These properties may further be acquainted with various ranges of GI values (Kaur et al. 2016). Researchers revealed that parboiled rice tended to show decreased glycemic response compared with non-parboiled rice (Pathiraje et al. 2010). The formation of resistant starch, as well as 
Table 3. Categorization of different rice varieties based on GI rankings

\begin{tabular}{lcccc}
\hline \multicolumn{1}{c}{ Rice Variety } & $\begin{array}{c}\text { Reference food } \\
\text { IAUC mmol/l min }\end{array}$ & $\begin{array}{c}\text { Test foods IAUC } \\
\text { mmol/1 min }\end{array}$ & GI & GI Class \\
\hline Nizershail & $244.2 \pm 20.1$ & $145.8 \pm 12.4$ & $59.7 \pm 3.4$ & Medium \\
BRRI Dhan 29 & $248.7 \pm 18.9$ & $125.6 \pm 8.7$ & $50.5 \pm 2.6$ & Low \\
Chinigura & $270.9 \pm 22.2$ & $156.5 \pm 11.3$ & $57.8 \pm 2.8$ & Medium \\
Kalijira & $305.6 \pm 19.7$ & $156.7 \pm 9.5$ & $51.3 \pm 2.3$ & Low \\
Hybrid Hera Dhan 12 & $325.4 \pm 5.3$ & $185.3 \pm 12.7$ & $56.9 \pm 3.9$ & Medium \\
Sworna & $251.1 \pm 16.3$ & $112.1 \pm 6.3$ & $44.6 \pm 2.1$ & Low \\
\hline
\end{tabular}

GI was obtained from IAUC variations of test foods in respect of their subsequent reference foods

Values are expressed as mean \pm SD; GI: Glycemic Index; IAUC: Incremental Area Under Curve

rice parboiling, gave rise to retrogradation of starch, which could be the reason behind such phenomenon (Wang et al. 2015).

Moreover, several factors such as starch types and their physical bindings with other food components, combinations of different contents of protein, fat, organic acids and their salts could contribute of GI values variations. It is already revealed that rice structure, for example, its coarse and fine forms, might express different GI value ranges. Usually fine rice (like white Bashmati) has low GI (Ranawanna et al. 2009) compared with coarse rice (brown Basmati) because of having more amylose: amylopectin ratio (Swetha 2019). The straight-chain form of starch is the amylose that does not gelatinize during cooking. Such depleted gelatinization caused low blood glucose and insulin level compared with fully cooked rice (Jung et al. 2009). In another study, a

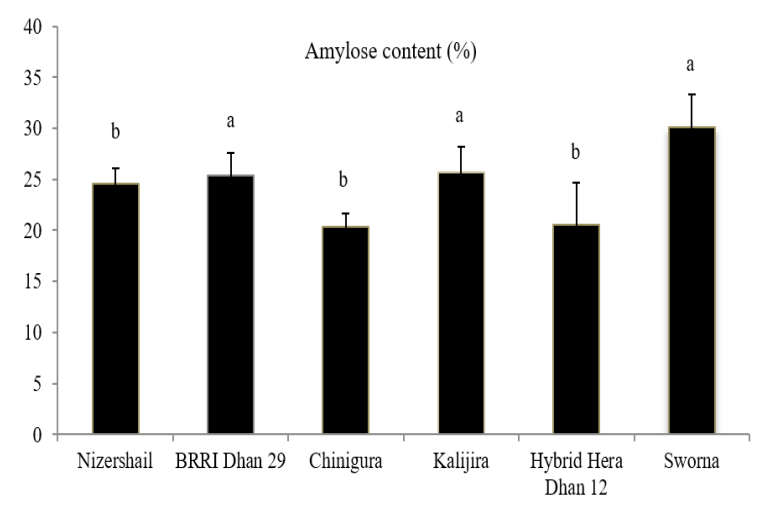

Figure 2. Amylose content (\%) in different rice varieties; Data (mean $\pm \mathrm{SD})$ are grouped into two classes by Duncan's Multiple Range Test high GI value was observed to be associated with a low (20\%) amount of amylose (Bhupathiraju et al. 2014).

In this study, an inverse relationship existed between the GI value and the amylose content of different rice varieties, which was similarly observed by Meera et al. (2019). High amylose content in the starch structure could slow down the digestion rate ( $\mathrm{Li}$ et al. 2020). Compared with the amylopectin structure, the amylose structure has a huge number of hydrogen bonds between the glucose units. Such more bindings could make the amylose more resistant to the digestive enzyme activity (Hong et al. 2018). On the contrary, the high amylopectin content are more prone to enzymatic action as compare to low amylose content (Xu et al. 2017). The observed GI values in this study could be further verified by the obtained amylose content, which established the inverse relationship.

\section{CONCLUSION}

In this in vivo investigation, six rice varieties that are commonly available in markets were taken into study. According to the classification of different GI groups, we could conclude that low GI rice varieties like BRRI Dhan 29, Kalijira and Sworna would be beneficial for different therapeutic controls in diabetic as well as normal individuals. Moreover, their amylose contents were subsequently higher, establishing an inverse proportion respective to their GI values.

The classification and recognition of the selected rice varieties of this study as low-GI 
Glycemic index of rice varieties in Bangladesh

and medium-GI foods would help consumers choose rice and rice based food products with a low glycemic response, thereby lowering and/or resisting the development diabetes. The grain quality of rice depends on the variation in production technology, preservation processes, cooking methods, and several other factors. Thus, it provides further scope to explore GI variation among different situation.

\section{ACKNOWLEDGEMENT}

This research work was conducted by the grant provided by Bangladesh Agricultural University Research System (BAURES project no. 2018/563 AU-GC). The authors are grateful to the selected volunteers and the physician Dr. Md. Shafiqul Haque of Mymensingh Medical College $\&$ Hospital for their contribution regarding the experiment.

\section{AUTHOR DISCLOSURES} of interests.

In this study, the authors have no conflict

\section{REFERENCES}

[AOAC] Association of Official Analytical Chemists. 2019. Official Methods of Analysis (21st edition). Washington DC (USA): AOAC.

Bhonsle SJ, Sellappan K. 2010. Grain quality evaluation of traditionally cultivated rice varieties of Goa, India. Receant Res Sci Technol 2:88-97.

Bhupathiraju SN, Tobias DK, Malik VS, Pan A, Hruby A, Manson JE, Willett WC, Hu FB. 2014. Glycemic index, glycemic load and the risk of type 2 diabetes: Results from 3 large US cohorts and an updated metaanalysis. Am J Clin Nutr 100(1):218-232. https://doi.org/10.3945/ajen.113.079533.

Brouns F, Bjorck I, Frayn KN, Gibbs AL, Lang V, Slama G, Wolever TM. 2005. Glycemic index methodology. Nutr Res Rev 18(1):145-171. https://doi.org/10.1079/ NRR2005100.

Duan DX, Donner E, Liu Q, Smith DC, Ravenelle F. 2012. Potentiometric titration for determination of amylose content of starch - A comparison with the colorimetric method. Food Chem 130(4):1142-1145. https://doi. org/10.1016/j.foodchem.2011.07.138.

[FAO/WHO] Food Agriculture Organization/ World Health Organization. 1998. Carbohydrates in human nutrition. Report of a joint $\mathrm{FAO} / \mathrm{WHO}$ expert consultation. FAO Food Nutr 66:1-140.

[FAO Newsroom] Food Agriculture Organization Newsroom. 2004. Rice is life. Food and Agricultural Organization of the United Nations, Rome, Italy. http://www.fao.org/ newsroom/en/focus/2004/36887/index. html [Accessed 12th February 2020].

GI Newsletter. 2019. "About glycemic index." Boden institute of obesity, nutrition, exercise and eating disorders and charles perkins centre at the university of Sydney. The University of Sydney. http://www. glycemicindex.com/about.php [Accessed 7th January 2021].

Hewson-Hughes AK, Gilham MS, Upton S, Colyer A, Butterwick R, Miller AT. 2011. The effect of dietary starch level on postprandial glucose and insulin concentrations in cats and dogs. Br J Nutr 106(S1):105-109. https://doi.org/10.1017/ S0007114511001887.

Hong J, Zeng XA, Buckow R, Han Z. 2018. Structural, thermodynamic and digestible properties of maize starches esterified by conventional and dual methods: Differentiation of amylose contents. Foods Hydrocoll 83:419-429. https://doi. org/10.1016/j.foodhyd.2018.05.032.

Jeevetha S, Nisak MYB, Ngan HB, Ismail A, Azlan A. 2014. Relationship between amylose content and glycemic index of commonly consumed white rice. IOSR Journal of Agriculture and Veterinary Science 7(9):12-18. doi:10.9790/238007931218.

Jenkins DJ, Wolever TM, Taylor RH, Barker $\mathrm{H}$, Fielden H, Baldwin JM, Bowling AC, Newman HC, Jenkins Al, Goff DV. 1981. Glycemic index of foods: A physiological basis for carbohydrate exchange. Am J Clin Nutr 34(3):362-366. https://doi. org/10.1093/ajen/34.3.362.

Jung EY, Suh HJ, Hong WS, Kim DG, Hong YH, Hong IS, Chang UJ. 2009. Uncooked rice of relatively low gelatinization degree 
resulted in lower metabolic glucose and insulin responses compared with cooked rice in female college students. Nutr Res 29(7):457-461. https://doi.org/10.1016/j. nutres.2009.07.002.

Kaur B, Ranawana V, Henry J. 2016. The glycemic index of rice and rice products: A review, and table of GI values. Crit Rev Food Sci Nutr 56(2):215-236. https://doi. org/10.1080/10408398.2012.717976.

Li N, Guo Y, Zhao S, kong J, Qiao D, Lin L, Lin Q, Zhang B. 2020. Amylose content and molecular-order stability synergistically affect the digestion rate of indica rice starches. Int J Biol Macromol 144:373-379. https://doi.org/10.1016/j. ijbiomac.2019.12.095.

Meera K, Smita M, Haripriya S, Sen S. 2019. Varietal influence on antioxidant properties and glycemic index of pigmented and nonpigmented rice. J Cereal Sci 87:202-208. https://doi.org/10.1016/j.jcs.2019.03.005.

Pathiraje PMHD, Madhujith WMT, Chadrasekara A, Nissanka SP. 2010. The effect of rice variety and parboiling on in vivo glycemic response. Tropical Agricultural Research 22(1):26-33.

Pinhero RG, Waduge RN, Liu Q, Sullivan JA, Tsao R, Bizimungu B, Yada RY. 2016. Evaluation of nutritional profiles of starch and dry matter from early potato varieties and its estimated glycemic impact. Food Chem 203:356-366. https://doi. org/10.1016/j.foodchem.2016.02.040.

Ranawanna DV, Henry CJK, Lightowler HJ, Wang D. 2009. Glycemic index of some commercially available rice and rice products in Great Britain. Int J Food Sci Nutr 60(Supp 4):99-110. https://doi. org/10.1080/09637480802516191.
Saez-Plaza P, Michalowski T, Navas MJ, Asuero AG, Wybraniec S. 2013. An overview of the Kjeldahl method of nitrogen determination. Part 1. Early history, chemistry of the procedure and the titrimetric finish. Crit Rev Anal Chem 43(4):178-223. https:// doi.org/10.1080/10408347.2012.751786.

Safita N, Islam SMS, Chow CK, Niessen L, Lechner A, Holle R, Laxy M. 2016. The impact of type 2 diabetes on health related quality of life in Bangladesh: Results from a matched study comparing treated cases with non-diabetic controls. Health Qual Life Outcomes 14(1):129. https://doi. org/10.1186/s12955-016-0530-7.

Saquib N, Saquib J, Ahmed T, Khanam MA, Cullen MR. 2012. Cardiovascular diseases and type 2 diabetes in Bangladesh: A systematic review and meta-analysis of studies between 1995 and 2010. BMC Public Health 12(1):434. https://doi. org/10.1186/1471-2458-12-434.

Swetha S. 2019. Which rice is best for a diabetic? Glycemic index analysis (part-1). Upgrade my food: making food fast healthy and fun. https://www.upgrademyfood.com/whichrice-is-best-for-a-diabetic-glycemicindex-analysis-part-1/ [Accessed 1st January 2019].

Wang S, Li C, Copeland L, Niu Q, Wang S. 2015. Starch retrogradation: A comprehensive review. Compr Rev Food Sci Food Saf 14(5):568-585. https://doi. org/10.1111/1541-4337.12143.

Xu J, Kuang Q, Wang K, Zhou S, Wang S, Liu X, Wang S. 2017. Insights into molecular structure and digestion rate of oat starch. Food Chem 220:25-30. https://doi. org/10.1016/j.foodchem.2016.09.191. 